\title{
The Gamma Ray Attenuations Of Superabsorbent Copolymer Poly(AA-co-Kry22 DM) Sorbed Se And Pb Atoms
}

\author{
A. Hakan Yilmaz ${ }^{*}$, T. Bayram¹, S. Savaşkan Yilmaz', Y. Misirlioğlu², A. Kucuk² \\ ${ }^{1}$ Department of Physics, Karadeniz Technical University \\ Trabzon, Turkey \\ hakany@ktu.edu.tr* corresponding author; t.bayram@ktu.edu.tr \\ ${ }^{2}$ Department of Chemistry, Karadeniz Technical University \\ Trabzon, Turkey \\ sevily@ktu.edu.tr; nisayzal@gmail.com; samedkucuk@outlook.com
}

\section{Extended Abstract}

The aim of this work is investigation on efficiency of superabsorbent copolymer, poly (AA-co-Kry22 DM) sorbed $\mathrm{Se}, \mathrm{Pb}$ atoms for gamma radiation protection. The poly (acrylic acid-copolymer-Kryptofix-22-DM) superabsorbent copolymer, poly(AA-co-Kry22-DM), was synthesized by the reaction of 4,13-dimethylacryloyl-1,7,10,16-tetraoxa-4,13 diazacyclooctadecane (Kyrptofix-22-DM) and acrylic acid (AA) by solution polymerization under vacuum in the Schlenk system. Characterization of the polymers was achieved by FTIR and ${ }^{1} \mathrm{H}$ NMR, SEM, TGA techniques. After this process we have investigated experimental gamma ray mass attenuation coefficients of "poly (AA-co-Kry22-DM)1 with Lead and Selenium composites as a function of gamma ray energy starting from $\sim 120 \mathrm{keV}$ to $\sim 1410 \mathrm{MeV}$. The results show that occurrences of $\mathrm{Se}$ and $\mathrm{Pb}$ elements in the structure of copolymers increase the total attenuation coefficients of copolymer dramatically between the gamma energy ranges of $\sim 120-800 \mathrm{keV}$. This result gives a clue for synthesizing of new polymer structures for producing radiation protective materials.

Based on the progress of nuclear science and technology applications, many studies are devoted to develop radiation protective materials. In particular lead is commonly used for protection from gamma ray because it is cheap and easily shaped and also it has high attenuation coefficient against gamma ray. On the other hand polymers are used in many technological applications and also there can be found many daily used materials produced by using various polymer structures. It can be considered that adding some elements with high gamma ray mass attenuation coefficients $\left(\sigma_{\mathrm{m}}\right)$ on polymers can provide useful and flexible material against gamma radiation. By considering this point we have investigated effect of adding $\mathrm{Se}$ and $\mathrm{Pb}$ atoms on poly (AA-co-Kry22-DM) for $\sigma_{\mathrm{m}}$ as a function of gamma energy.

The poly (AA-co-Kry22 DM) superabsorbent used in the gamma radiation study was synthesized [1] by us in the Polymer Chemistry Laboratory of Karadeniz Technical University using the similar method in the literature [2]. FTIR and ${ }^{1} \mathrm{H}$ NMR figures of Kry22-DM and Poly(AA-co-Kry22-DM) superabsorbent copolymer are presented in the literature [1]. The characterization of Kry22-DM was achieved by FTIR and ${ }^{1} \mathrm{H}$ NMR techniques. ${ }^{1}{ }^{1} \mathrm{H}$ NMR spectrum of Kry22-DM shows the characteristic peaks at $1620 \mathrm{~cm}^{-1}$ for $-\mathrm{C}=\mathrm{O}$ - groups, at $1110 \mathrm{~cm}^{-1}$ for $-\mathrm{C}=\mathrm{O}$ - groups, at 2868 $2980 \mathrm{~cm}^{-1}$ for $-\mathrm{CH}_{3}$ and $-\mathrm{CH}_{2}$ groups, at $2850 \mathrm{~cm}^{-1}$ for $-\mathrm{C}-\mathrm{N}$ - groups, and at $1350-1370 \mathrm{~cm}-1$ for methyl symmetrical deformation peaks. FTIR spectrum ${ }^{1}$ of the crosslinked poly(AA-co-Kry22-DM) superabsorbent copolymer shows the characteristic peaks at $1713 \mathrm{~cm}^{-1}$ for-C $=\mathrm{O}$ - groups, at $1161 \mathrm{~cm}^{-1}$ for $-\mathrm{C}-\mathrm{O}$-groups, at $2648 \mathrm{~cm}^{-1}$ for $-\mathrm{C}-\mathrm{N}$ - groups, at 2700 $3500 \mathrm{~cm}^{-1}$ for $-\mathrm{COOH}$ groups, at $2840-2950 \mathrm{~cm}^{-1}$ for $-\mathrm{CH} 3$ and $-\mathrm{CH} 2$ groups, and $1406 \mathrm{~cm}^{-1}$ for methyl symmetrical deformation peaks. In this work, the absorption of gamma radiation of poly(AA-co-Kry22-DM)-matrix composites with reinforcing set numbers are following :

1. poly(AA-co-Kry22-DM) superabsorbent

2. poly(AA-co-Kry22-DM) superabsorbent + Se $(10 \%)$

3. poly(AA-co-Kry22-DM) superabsorbent $+\mathrm{Se}(30 \%)$

4. poly(AA-co-Kry22-DM) superabsorbent $+\mathrm{Pb}(10 \%)$

5. poly(AA-co-Kry22-DM) superabsorbent $+\mathrm{Pb}(30 \%)$

For experimental determination of $\sigma_{\mathrm{m}}$ of the mentioned composites HPGe detector system at Nuclear Physics Laboratory of Karadeniz Technical University has been used. Also Eu point radiation source with $121.8 \mathrm{keV}, 244.7 \mathrm{keV}$, $344.3 \mathrm{keV}, 778.9 \mathrm{keV}, 964 \mathrm{keV}, 1112.1 \mathrm{keV}$ and $1408 \mathrm{keV}$ gamma energy has been used. For data analysis Gamma Vision computer program was used. For determination of $\sigma_{\mathrm{m}}$ of these composites sample weight and area have measured. 
For each gamma energy of Eu point source detector counts with sample and without sample had been taking into account for calculating of $\sigma_{\mathrm{m}}$.

In the present study $\sigma_{\mathrm{m}}$ values for all examples have decreased when gamma energy increased as one can expected [3]. It can be clearly observed that adding lead and selenium on poly superabsorbent has increased the $\sigma_{\mathrm{m}}$ values dramatically in the present study. For this, the best example of this study obtained for poly(AA-co-Kry22-DM) superabsorbent $+\mathrm{Pb}(30 \%)$ sample. For pure poly (AA-co-Kry22-DM) superabsorbent sample $\sigma_{\mathrm{m}}$ values $0.332 \mathrm{~cm}^{2} / \mathrm{g}$, $0.326 \mathrm{~cm}^{2} / \mathrm{g}, 0.701 \mathrm{~cm}^{2} / \mathrm{g}, 0.638 \mathrm{~cm}^{2} / \mathrm{g}, 0.422 \mathrm{~cm}^{2} / \mathrm{g}, 0.054 \mathrm{~cm}^{2} / \mathrm{g}$ and $0.222 \mathrm{~cm}^{2} / \mathrm{g}$ are determined for the gamma energy values $121.8 \mathrm{keV}, 244.7 \mathrm{keV}, 344.3 \mathrm{keV}, 778.9 \mathrm{keV}, 964 \mathrm{keV}, 1112.1 \mathrm{keV}$ and $1408 \mathrm{keV}$, respectively. However, for poly(AA-co-Kry22-DM) superabsorbent $+\mathrm{Pb}(30 \%)$ composite $\sigma_{\mathrm{m}}$ values $2.709 \mathrm{~cm}^{2} / \mathrm{g}, 2.177 \mathrm{~cm}^{2} / \mathrm{g}, 1.827 \mathrm{~cm}^{2} / \mathrm{g}, 1.094$ $\mathrm{cm}^{2} / \mathrm{g}, 0.873 \mathrm{~cm}^{2} / \mathrm{g}, 0.432 \mathrm{~cm}^{2} / \mathrm{g}$ and $0.225 \mathrm{~cm}^{2} / \mathrm{g}$ are determined for the gamma energy values $121.8 \mathrm{keV}, 244.7 \mathrm{keV}$, $344.3 \mathrm{keV}, 778.9 \mathrm{keV}, 964 \mathrm{keV}, 1112.1 \mathrm{keV}$ and $1408 \mathrm{keV}$, respectively. Particularly this study can possibly indicate that occurrences of $\mathrm{Pb}$ elements in the structure of copolymers increase the total attenuation coefficients of copolymer dramatically between the gamma energy ranges of $\sim 120-800 \mathrm{keV}$. From this point one can conclude that poly (AA-coKry22-DM) superabsorbent $+\mathrm{Pb}(30 \%)$ composite can be used for gamma radiation protection material because it has flexible character and easy production.

Keywords: Superabsorbents and Metal Composites, Gamma Radiation, Mass Attenuation Coefficient, Radiation Protection.

\section{References}

[1] S. S. Yilmaz, D. Kul, M. Erdol, M. Ozdemir, R. Abbasoglu, "Synthesis of a novel crosslinked superabsorbent copolymer with diazacyclooctadecane crown ether and its sorption capability," European Polymer Journal, vol. 43, pp. 1923-1932, 2007.

[2] F. L. J. Buchholz, "Superabsorbent Polymers: An Idea Whose Time Has Come," Chem Edu, vol. 73, pp. 512-5, 1996.

[3] J. H. Hubbell, S. M. Seltzer, "Tables of X-Ray Mass Attenuation Coefficients and Mass Energy-Absorption Coefficients from $1 \mathrm{keV}$ to $20 \mathrm{MeV}$ for Elements Z=1 to 92 and 48 Additional Substances of Dosimetric Interest," X-Ray Mass Attenuation Coefficients, Physical Measurement Laboratory, NIST. [Online]. Available: https://www.nist.gov/pml/x-ray-mass-attenuation-coefficients 